UCRL- 101766

PREPRINT

\title{
A High Temperature, Plasma-Assisted Chemical \\ Vapor Deposition System
}

\author{
R.M. Brusasco \\ J.A. Britten \\ C.B. Thorsness \\ M.S.Scrivener \\ W.G. Unites \\ J.H. Campbe 11 \\ W.L. Johnson \\ 1989 \\ Boulder Damage Symposium \\ Boulder, CO \\ November 1-3, 1989

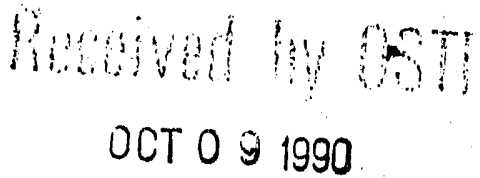

February 1990

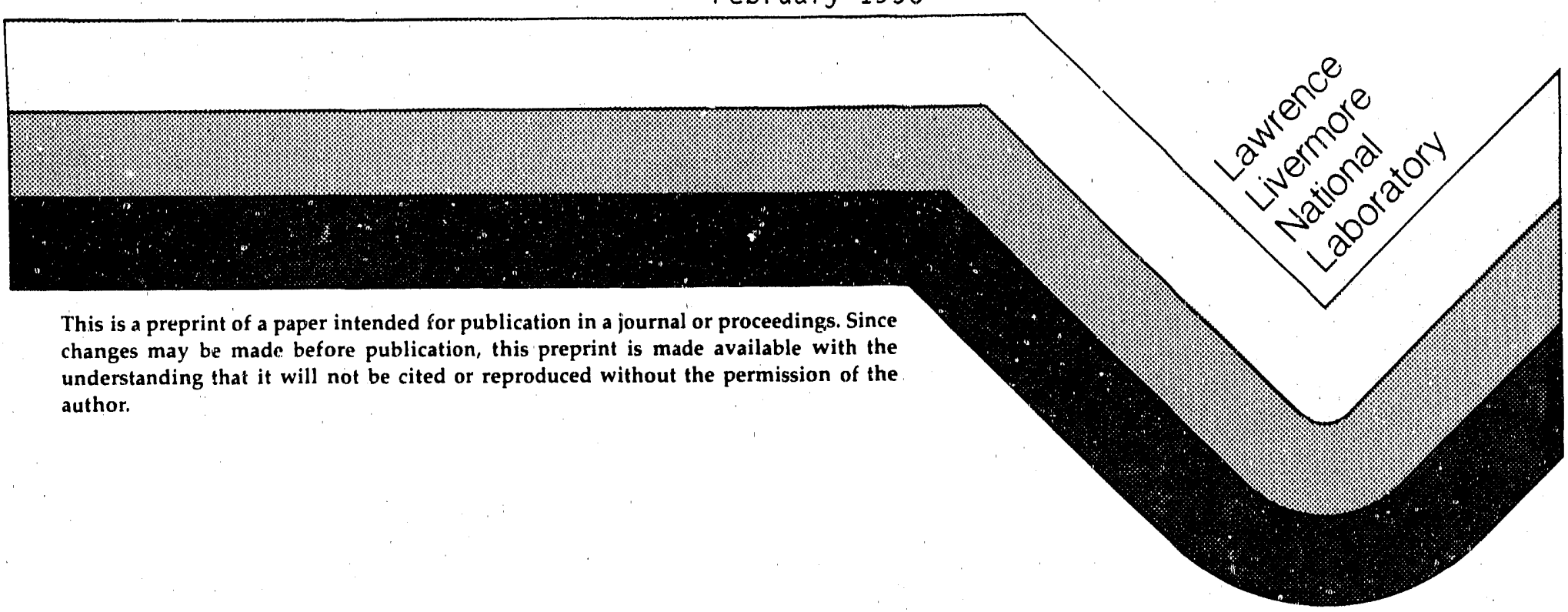

DISTRIBUTION OF THIS DOCUMENT IS UNLIMITE: 


\section{A High Ternperature, Plasma-Assisted \\ Chemical Vapor Deposition System*}

R. M. Brusasco, J. A. Britten, C. .B. Thorsness,

M. S. Scrivener, W. G. Unites, and J. H. Campbell

University of California

Lawrence Livermore National Laboratory

P.O. Box 5508, L-490

Livermore, CA 94550

W.L. Johnson

Prototech Research, Inc.

106 South 54th Street

Chandler, AZ 85226

We have designed and built a high-temperature, plasma-assisted, chemical vapor deposition system to deposit multilayer optical coatings of $\mathrm{SiO}_{2}$ and doped-SiO $\mathrm{S}_{2}$ on flat substrates. The coater concept and design is an outgrowth of our recent work with Schott Glaswerke demonstrating the use of plasma assisted CVD to prepare very high damage threshold optici.icoatings. (That work is reported in a companion paper at this Symposium).

The coater is designed to deposit up to several thousand alternating quarterwave layers of $\mathrm{SiO}_{2}$ and doped $\mathrm{SiO}_{2}$ on $\mathrm{SiO}_{2}$ substrates at deposition rates up to several microns per minute. The substrate is resistively heated to about $1000^{\circ} \mathrm{C}$ during the deposition phase of the process. The plasma is driven by a $13.56 \mathrm{MHz}$ RF unit capable of producing power densities of up to $140 \mathrm{~W} \mathrm{~cm}^{-3}$ in the reaction zone. The coater is designed to be adaptable to microwave generated plasmas, as well as RF. Reactant gas flow rates of up to $10 \mathrm{sim}$ can be achieved at a 10 torr operating pressure. Reactants consist of $\mathrm{O}_{2}$, SiCl and a volatile halogenated dopant (e.g. $\mathrm{GeCl}_{4}$ or $\mathrm{CCl}_{2} \mathrm{~F}_{2}$ ). These gases react in the plasma volume producing $\mathrm{SiO}_{2}$ with dopant concentrations (e.g. $\mathrm{GeO}_{2}$ ) of up to a few percent. A variable dopant concentration is used to produce index differences (nominally about 0.01 ) between adjacent optical layers.

"Work performed under the auspices of the U.S. Department of Energy by Lawrence Livermore National Laboratory under contract number W-7405-ENG-48. 
Some of the major technical problems associated with the design and construction of this coater are discussed. These include flow distribution and its effect on deposition uniformity, substrate heater design and operation, choice of RF vs. microwave driven plasma and diagnostics design and placement. To address many of these issues, we have relied heavily on numerical and experimental modeling of the fluid flow, reaction kinetics, and heat transfer within the coater. Furthermore, preliminary experiments carried out on prototype designs were used to guide our development efforts.

\subsection{Introduction}

High reflectivity (HR) coatings for the next generation laser fusion driver will require laser damage thresholds not less than $40 \mathrm{~J} / \mathrm{cm}^{2}$ at $1.06 \mu$ wavelength[1]. Considering that bulk fused silica possesses a high laser damage threshold and is made by high temperature chemical vapor deposition, an effor has been initiated to apply a high temperature deposition method to the creation of a multilayer HR reflector. This so-called "kilolayer" concept, and its success in a circular tube geometry, is described more fully in another paper in this publication[2]. The key processing issue now is to translate this process to one suitable for flai substrates.

The task requires separation into four roughly concurrent efforts; preliminary experimentation with the coating process, examination of heat and mass transport issues, investigation of fundamental plasma characteristics and hardware production and evaluation. With respect to mass transport, Wilcock et al.[3] and Law and Masliyah [4] have successfully used naphthalene sublimation in the analysis of mass transport uniformity. Since, mathematically, naphthalene sublimation (removal) is equivalent to deposition in terms of uniformity, we constructed a test bed to model the mass transport in the proposed reaction chamber geometry. We wished to determine whether the proposed geometry would lead to a uniform deposition and what the critical parameters were that would assure uniform mass transport.

With respect to plasma characteristics, we have demonstrated deposition of up to $\approx 5000$ quarter wave layers inside a $3.0 \mathrm{~cm}$ diameter tube[2] using $2.45 \mathrm{GHz}$ radiation to excite the plasma. However, the ability to scale plasma applicators at $2.45 \mathrm{GHz}$ uniformly for large flat substrates, the cost of such scaleup and possible use of other radiation frequencies remain unresolved issues. As an examiple of frequericy dependence, two literature studies concerning a photoresist stripping process can be used to compare RF versus microwave plasmas. The papers by Dzioba et al.[5] and Degenkolb et al.[6,7], describe experimental systems that are nearly identical, with similar reaction volumes, pressures, and oxygen flow rates. However, the study utilizing $2.45 \mathrm{GHz}$ exhibited a more highly-excited oxygen plasma environment, inferred from the optical emission spectrum, and an order-of-magnitude increase in the stripping rate compared to the study which used $13.56 \mathrm{MHz}$ radiation. The extent to which differences such as this would affect our CVD coating apparatus is unknown at this time, but could have a large impact in terms of hardware development and coating performance, particularly laser damage resistance. We have constructed a plasma test bed to investigate the differences between RF and microwave plasmas and to refine plasma diagnostic techniques.

Among the diagnostic techniques being considered for monitoring the coating environment are residual gas analysis for mass balance and impurity monitoring and determination of the electron density $\left(n_{\bullet}\right)$ and electron temperature $\left(T_{0}\right)[8]$ with a Langmuir probe. 


\subsection{Experimental}

Preliminary deposition studies were carried out in a horizontal silica tube reactor, shown schematically in figure 1. ine tube was $7.62 \mathrm{~cm}$ in diameter (expanded to $12 \mathrm{~cm}$ in the reaction zone) and approximately $61 \mathrm{~cm}$ long. The tube was contained in a radiantly heated furnace with the heating zone approximately $30 \mathrm{~cm}$ long. A thimble coniaining a fused silica substrate, a graphite susceptor and a boron nitride insulator was inserted into the hot zone of the reaction tube. The graphite served as the absorber in the radiant furnace and as the driven electrode for the application of RF at $13.56 \mathrm{MHz}$. Gas flows of oxygen, silicon tetrachloride and germanium tetrachloride were established using mass flow controllers. Pressures were monitored with Baratron gauges and controlled by a butterfly valve controller. Typical operating parameter ranges are given in table 1.

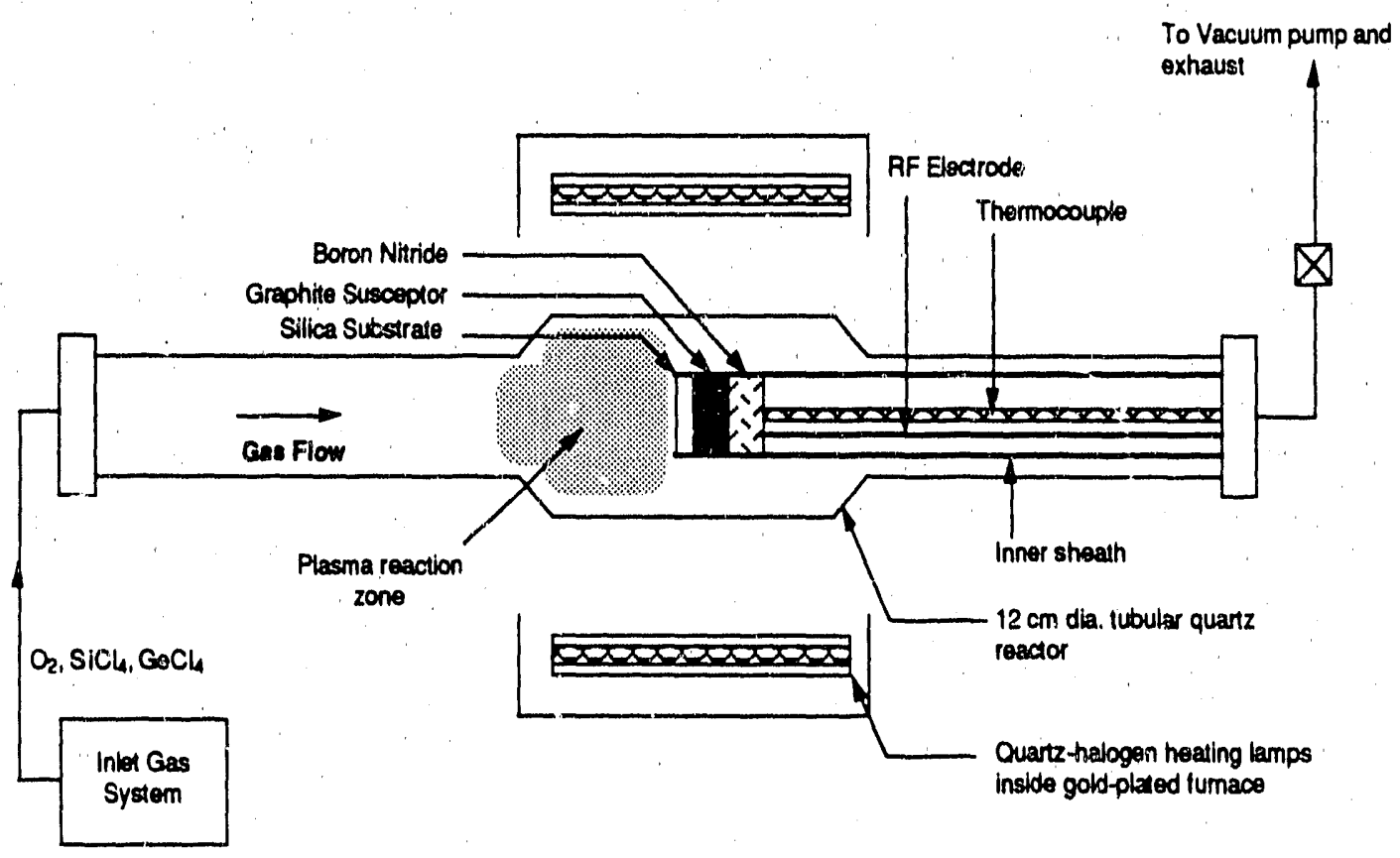

Figure 1. Schemalic of radiantly healed plasma CVD reactor.

Mass transfier experiments were performed in a 1:1 scale model of the proposed coater (fig. 2) with a reaction volume of approximately $800 \mathrm{~cm}^{3}$ [9]. The substrate-to-injection plate spacing could be adjusted with appropriately sized spacers. A Duo Seal 1398 vacuum pump allowed pumping rates as high as 5 sim through the reactor at reaction chamber pressures from 200 to $2000 \mathrm{~Pa}$. A gas distribution plate consisting of a square array of 237 holes of $0.0635 \mathrm{~cm}$ diameter on $1 \mathrm{~cm}$ centers or 72 holes of $0.229 \mathrm{~cm}$ diameter on $1 \mathrm{~cm}$ centers was studied. Substrates were prepared by hot pressing naphthalene at approximately $78^{\circ} \mathrm{C}$ and $68 \mathrm{MPa}$ pressure into aluminum molds. The substrates were weighed before and after the sublimation experiment to determine the mass of naphthalene that sublimed and from this an average rate of removal was calculated. The substrate surface was also profiled vefore and after a run on a Moore profilometer (resolution $3 \times 10^{-4} \mathrm{~cm}$ ) to determine uniformity of sublimation. 
Table 1. Summary of typical operating conditions used in our preliminary radiant heating plasma CVD experiments

\section{Pressure}

Flow rate oxygen

Flow rate $\mathrm{SiCl}_{4}$

Flow rate $\mathrm{GeCl}_{4}$

RF power (CW exp.)

RF power (peak)

RF power (average)

Pulse width

Pulse Repetition Frequency

Temperature

Reaction time

Number of experimental runs
0.3-3.0 torr

$100-500 \mathrm{sccm}$

$20.90 \mathrm{sccm}$

$0-10 \mathrm{sccm}$

300 Watts

57-94 Watts

8.5-15 Watts

$10-15 \times 10^{-3} \mathrm{sec}$

$10-30 \mathrm{~Hz}$

$1050-1250^{\circ} \mathrm{C}$

$60 \mathrm{~min}$.

16

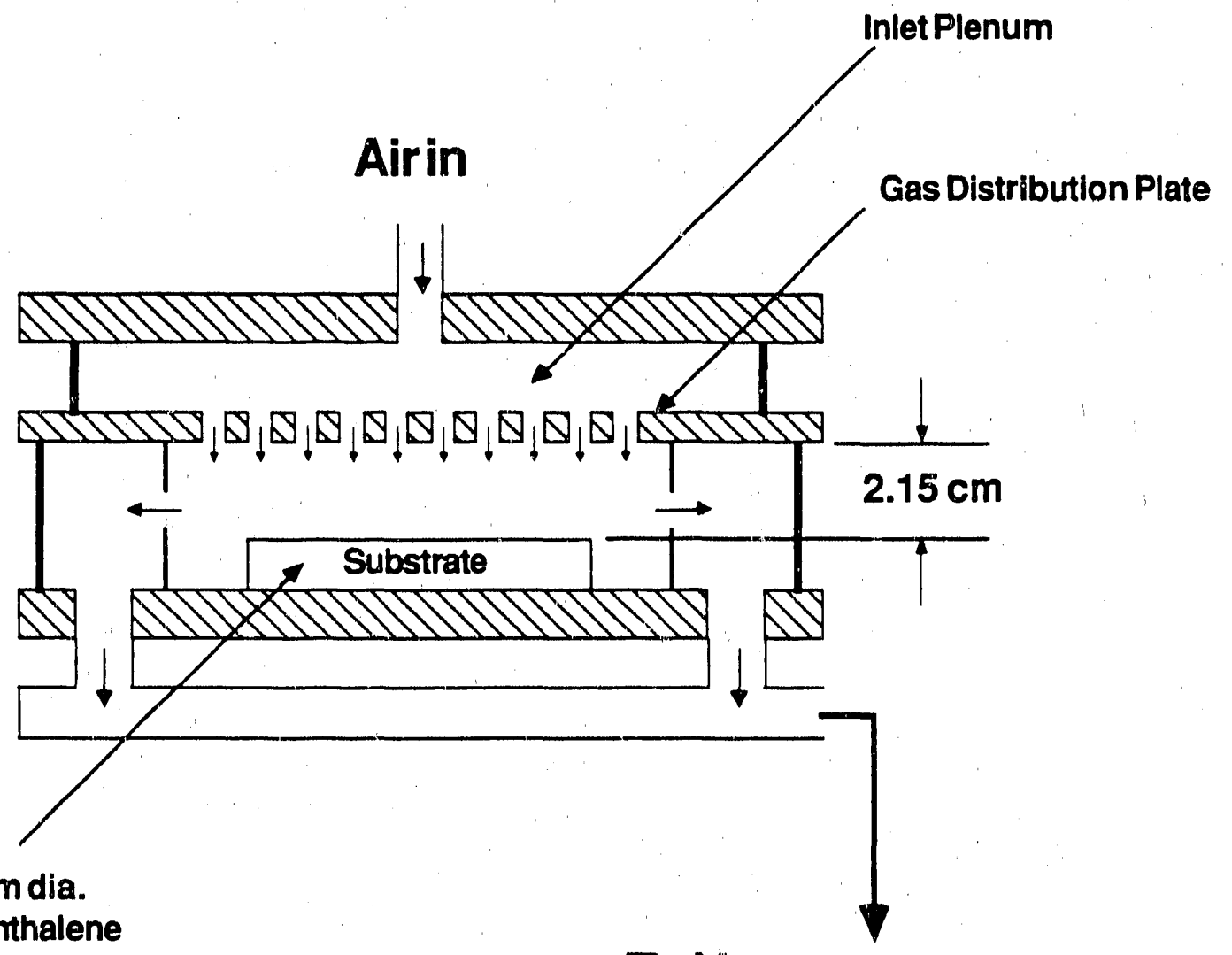

$15 \mathrm{~cm}$ dia.

Naphthalene

Substrate

ToVacuum

Figure 2. Schematic of the mass-transfer test system 
Initial experiments on plasma characteristics were carried out in a silica reactor. Langmuir probe experiments were done in a horizontal fused silica tube of $15 \mathrm{~cm}$ diameter in the reaction zone and an overall length of $90 \mathrm{~cm}$, as shown in figure 3. The plasma was excited by RF at $13.56 \mathrm{MHz}$ using $2.5 \mathrm{~cm}$ wide strips of metal as electrodes that were attached to the outside of the reactor tube in a clam-shell arrangement. The Langmuir double probe was constructed as described by Chen [10] and placed as close to the electrodes as possible and extended into the plasma region approximately $5 \mathrm{~cm}$. Fresently, diagnostics experiments are conducted in a full scale mock-up of the proposed PCVD coater geometry as shown in figure 4, with a diameter of $15 \mathrm{~cm}$ and a height adjustable from 1 to $7 \mathrm{~cm}$. The plasma is excited by either a parallel plate RF electrode arrangement, with the driven electrode at the bottom of the chamber, or with a waveguide applicator for $2.45 \mathrm{GHz}$ radiation. A residual gas analysis system using an Inficon Quadrex 100 Residual Gas Analyzer (RGA) was attached to the exhaust port of the test chamber.

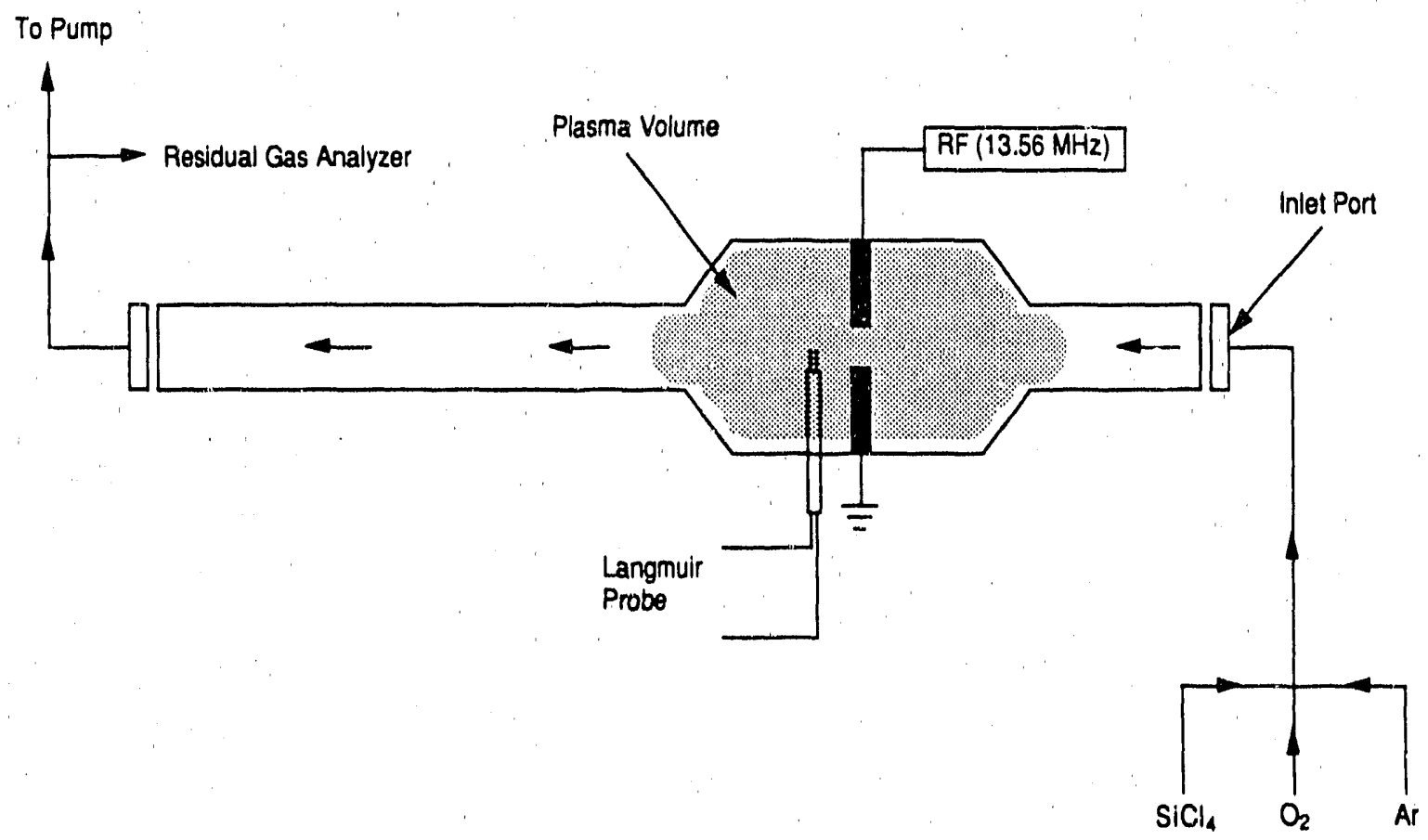

Figure 3. Schematic of tubular plasma test bed

\subsection{Results and Discussion}

\subsection{Preliminary Depusition Experiments}

Preliminary deposition experiments using $13.56 \mathrm{MHz}$ RF to drive the reactive plasma in the horizontal, radiantly heated furnace pointed out several significant problem areas. First, the substrate temperature was difficult to determine. The thermocouple monitor could only read the back of the susceptor and was influenced by the driving RF electric field. Second, the deposited layers were uneven and contained particulates. The existence of cold walls in contact with the process caused generation of particulate silica, which found its way onto the growing film. Also, there was considerable leakage of the plasma into undesirable areas of the reactor, such as directly behind the susceptor and along the walls of the thimble. This leakage significantly reduced the plasma power density available in the reaction volume. In addition, the total RF power available was only $1 \mathrm{~kW}$. 


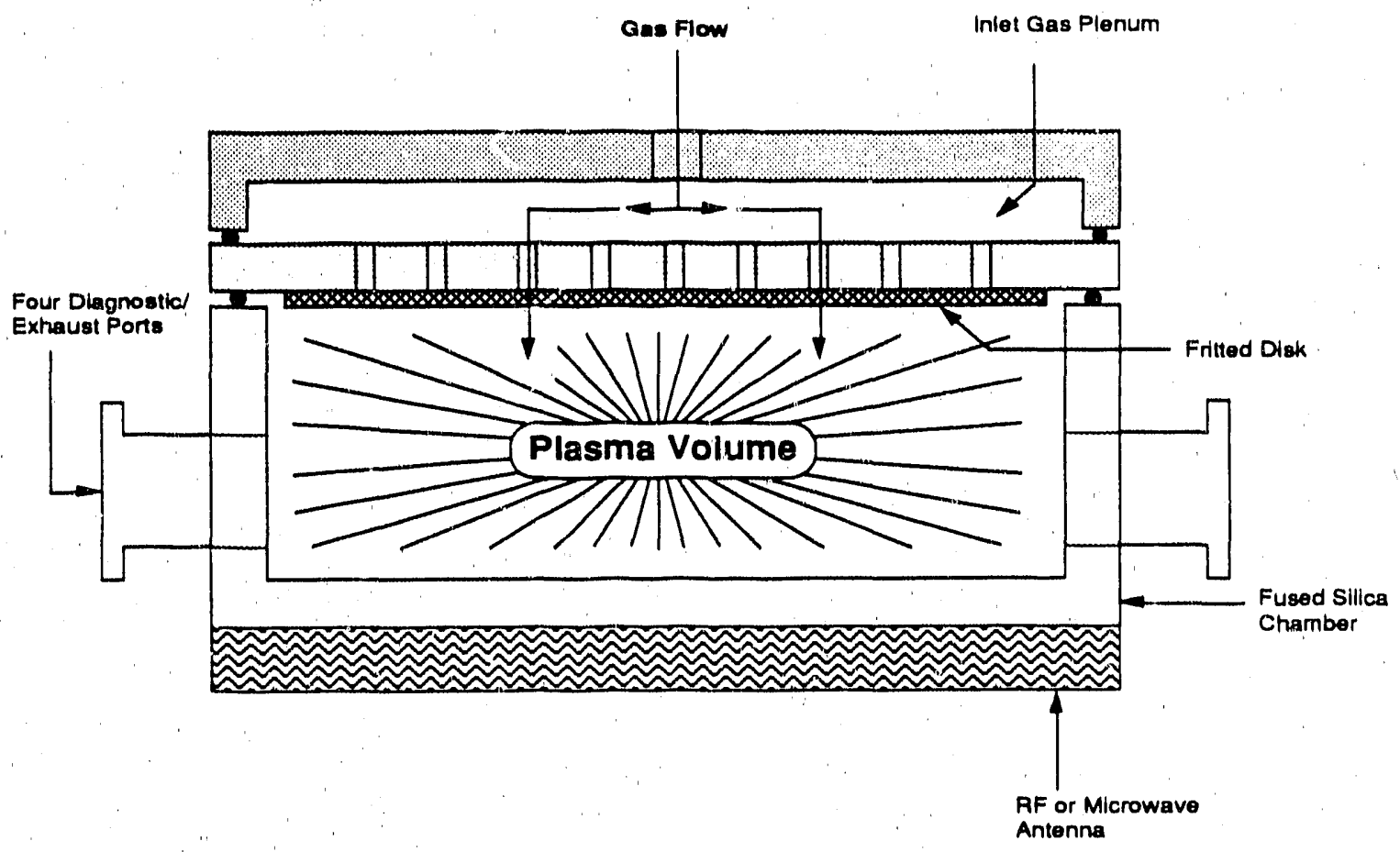

Figure 4. Schematic of parallel-plate plasma test bed.

\subsection{Mass Transport}

Figure 5 shows the surface profile of a naphthalene disk before and after a sublimation run where the disk was exposed to $2 \mathrm{sim}$ ilow for 5 hours to remove approximately $50 \%$ of the naphthalene material. The increased surface roughness following sublimation is atributed to the crystalline nature of the naphthalene causing preferential removal based on grain orientation. The mass removal rate was greater at the outer edge of the disk than at the center due to edge effects associated with a finite disk size. An analysis of the radial removal rate versus total amount of material removed, neglecting the outer $4.5 \mathrm{~cm}$ edge, shows the uniformity to be $\pm 5 \%$. Figure 6 compares the dimensionless mass transfer rate versus Reynolds number $(R e)$ for experiment with that predicted by stagnation flow theory assuming uniform gas injection through the top plate. Here we define the Reynolds number as,

$$
R_{0}=\frac{H V}{\eta}
$$

where $H$ is the distance separating the gas injection plate and substrate $(\mathrm{cm}), V$ is the superficial axial injection velocity $(\mathrm{cm} / \mathrm{sec})$ and $\eta$ is the kinematic gas viscosity $\left(\mathrm{cm}^{2} / \mathrm{sec}\right)$. The mass transfer rate is made dimensionless by,

$$
y^{\prime}=\left(\frac{W}{t A}\right)\left(\frac{P}{P_{\text {sat }}}\right)\left(\frac{H}{D \rho M}\right)
$$


where:

$$
\begin{array}{ll}
W & =\text { Mass loss }(\mathrm{gm}) \\
t & =\text { time }(\mathrm{s}) \\
A & =\text { Naphthalene surface area }\left(\mathrm{cm}^{2}\right) \\
P & =\text { Pressure (torr) } \\
P_{\text {sat }} & =\text { Naphthalene vapor pressure (torr) } \\
H & =\text { Reactor height }(\mathrm{cm}) \\
D & =\text { Naphthalene diffusivity in air }\left(\mathrm{cm}^{2} / \mathrm{s}\right) \\
\rho & =\text { Gas density }\left(\mathrm{g} / \mathrm{cm}^{3}\right) \\
M & =\text { Molecular weight naphthalene }(\mathrm{gm})
\end{array}
$$

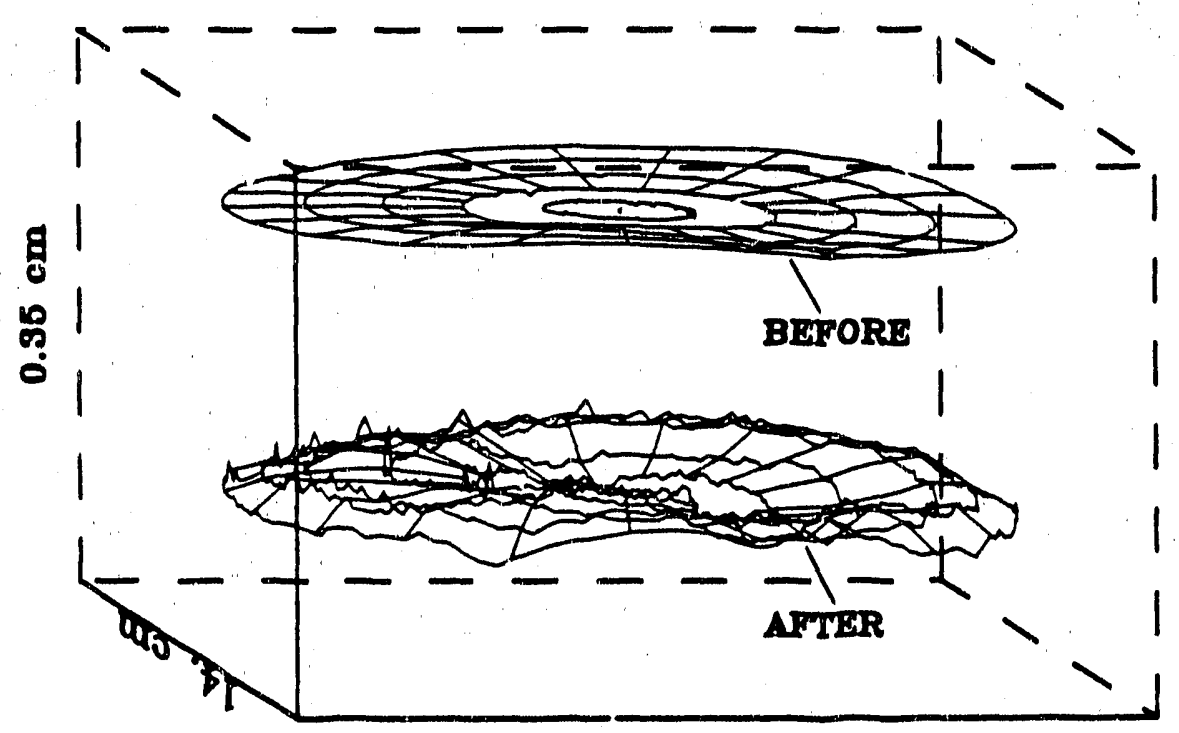

14. $\mathrm{cm}$

Figure 5. Plot of the naphthalene disk surface contour before and after evaporation.

For low Reynolds numbers, the mass transfer rate agrees with the stagnation flow theory [11] and the removal of naphthalene is uniform. Above a Reynolds number of about 3 the mass removal rate increases sharply due to jet impingement as shown in figure 7 . Here, jet impingement has caused locally high mass removal directly under the inlet orifices, causing a dimpling of the naphthalene surface. These studies have defined flow rate ranges, for a given reactor and gas distribution geometry, that lead to radially uniform mass transfer in the reactor; further details of this work are given in ref. 9.

\subsection{Plasma Characterization}

Figure 8 shows some preliminary data faken from Residual Gas Analysis of a mixture of $\mathrm{O}_{2}$ and $\mathrm{SiCl}_{4}$ exposed to an RF plasma. A very low baseline of oxygen gas is compared with a mixture of $\mathrm{O}_{2}$ and $\mathrm{SiCl}_{4}$ without plasma, which reveals the fragmentation pattern of silicon tetrachloride. Upon striking the plasma, the fragmentation pattern indicates a dramatic increase in the signal at mass 70 , attributed to $\mathrm{Cl}_{2}$ 
parention, with corresponding decreases in the masses of the lower silicon halldes. Residual gas analysis will be useful in characterizing the stable volatile reaction products as well as monitoring the presence of impurities in the gas streams. The major improvement here will be the calibration of the instrument to provide a mass balance for the reactants and products and to increase the mass range such that all fragments of $\mathrm{SiCl}_{4}$ and dopants can be monitored routinely.

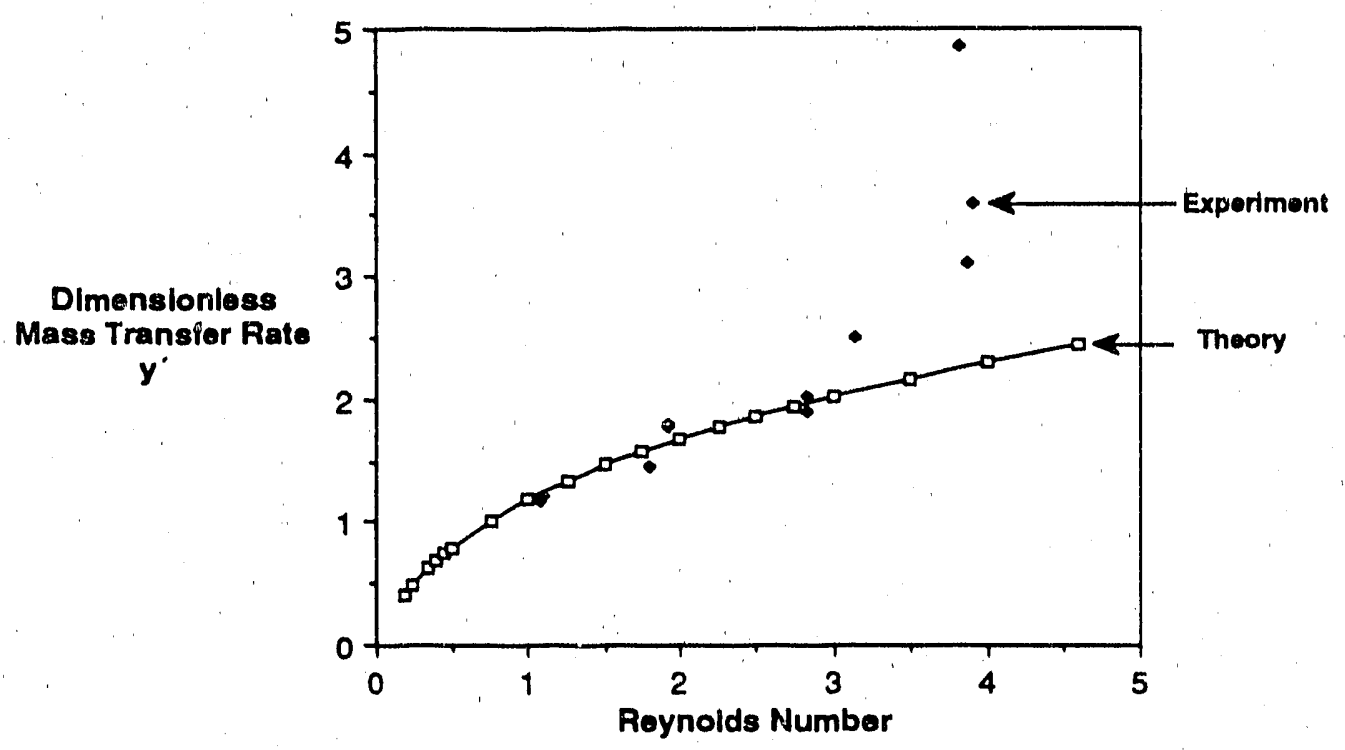

Figure 6. Dimensionless mass transfer rate versus Reynolds number

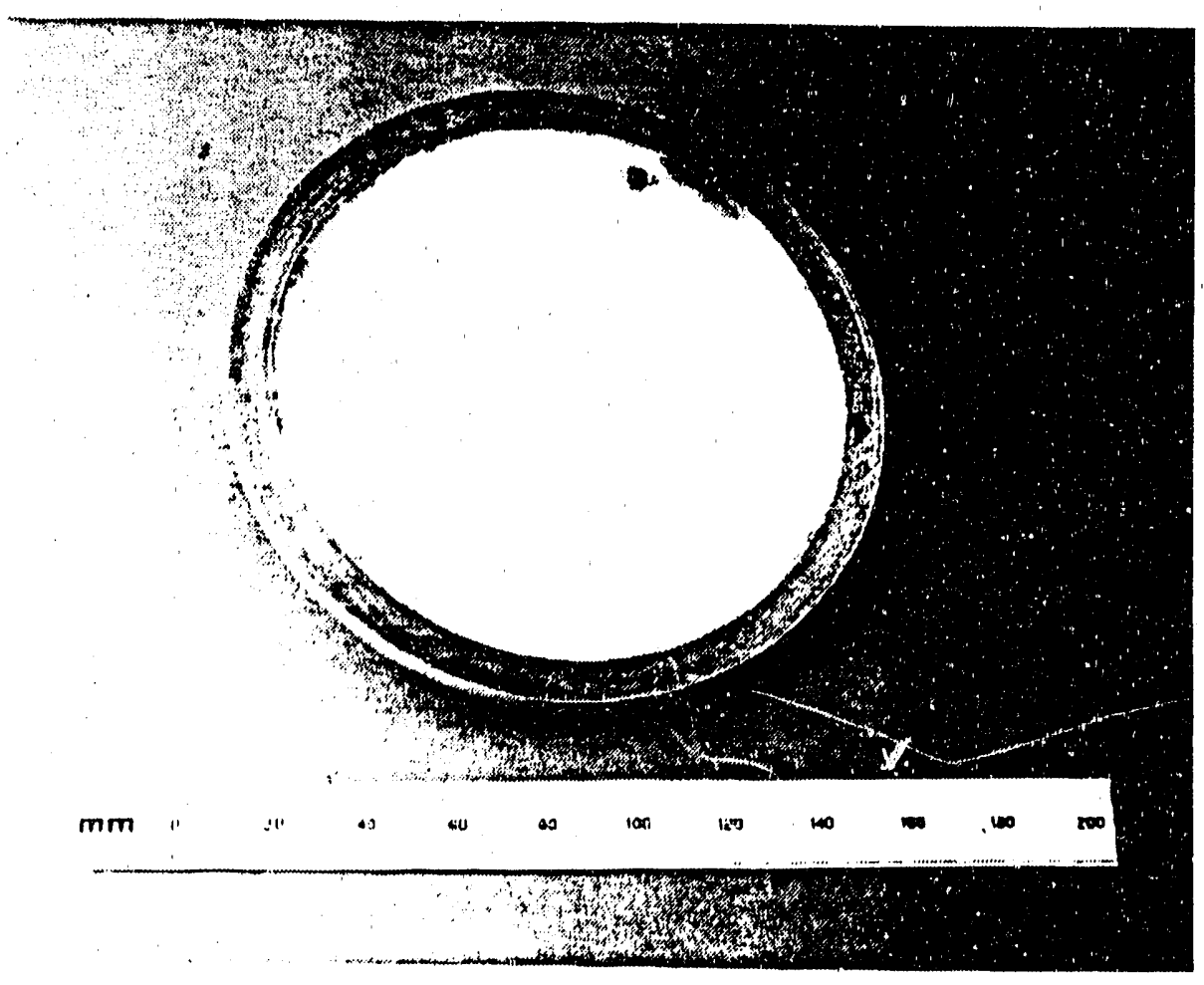

Figure 7. Photo of jet impingement on a naphthalene disk. 


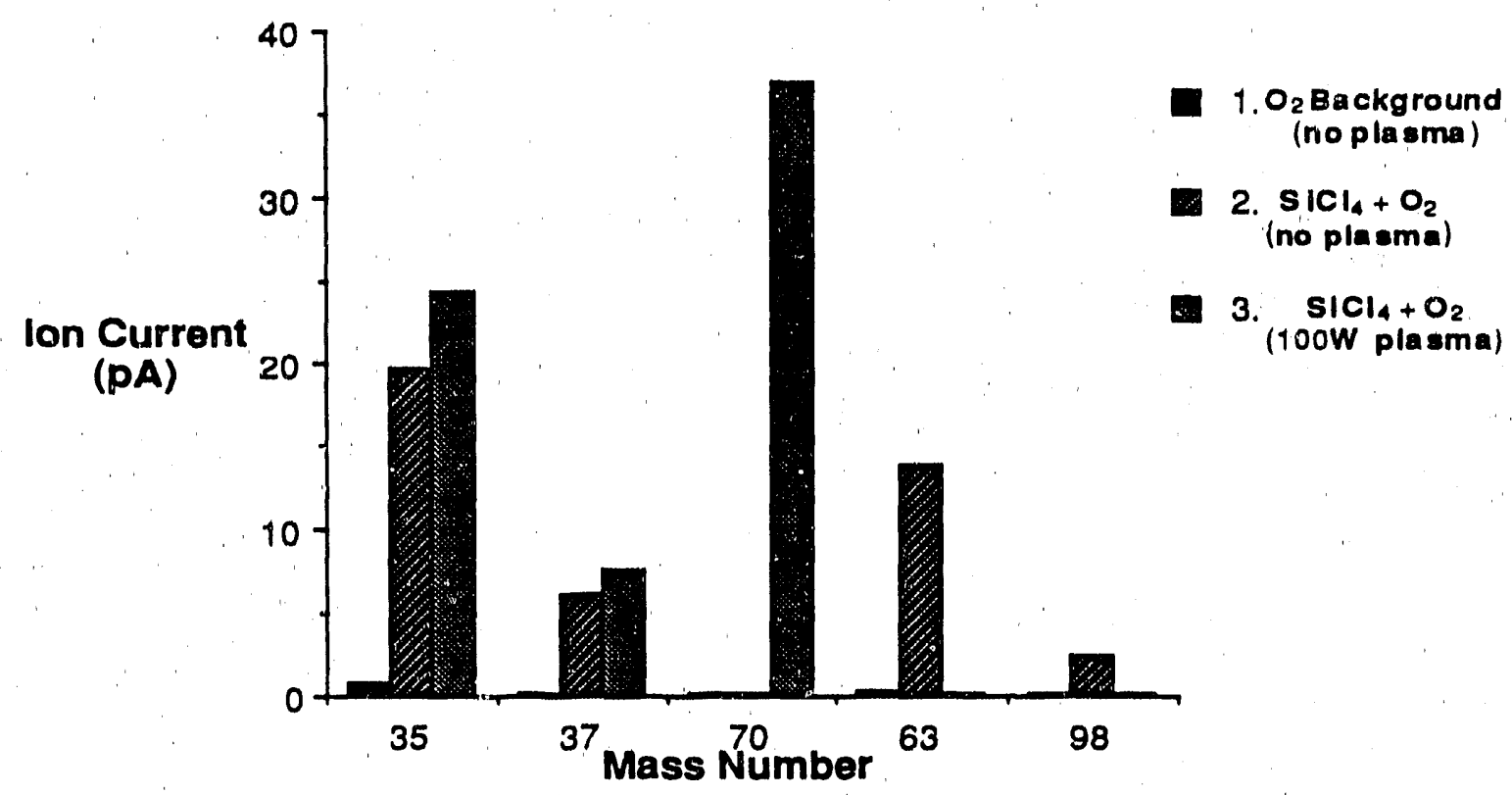

Figure 8. Residual Gas Analysis of coater effluent with and without plasma.

Current-voliage data were taken with a Langmuir double probe in oxygen at 1 torr pressure at several 13.56 MHz RF power levels. Figure 9 shows that with increasing RF power, the electron temperature increases from about $4 \mathrm{eV}$ at 50 watts to approximately $6 \mathrm{eV}$ at 150 watts. Similarly, the electron density increases from about $6.0 \times 10^{\circ} \mathrm{cm}^{-3}$ at 50 watts to $1.3 \times 10^{10} \mathrm{~cm}^{-3}$ at 150 watts. These data are in qualitative agreement with data from Heidenreich et al. [12] investigating oxygen microwave afterglows and Yamagishl et al. [13] investigating air-helium plasmas excited by several methods. The key developments in Langmuir probe measurements will be to extend their operation at high power densities and in the electronegative plasmas anticipated in the coater environment.

\section{Langmuir Probe}

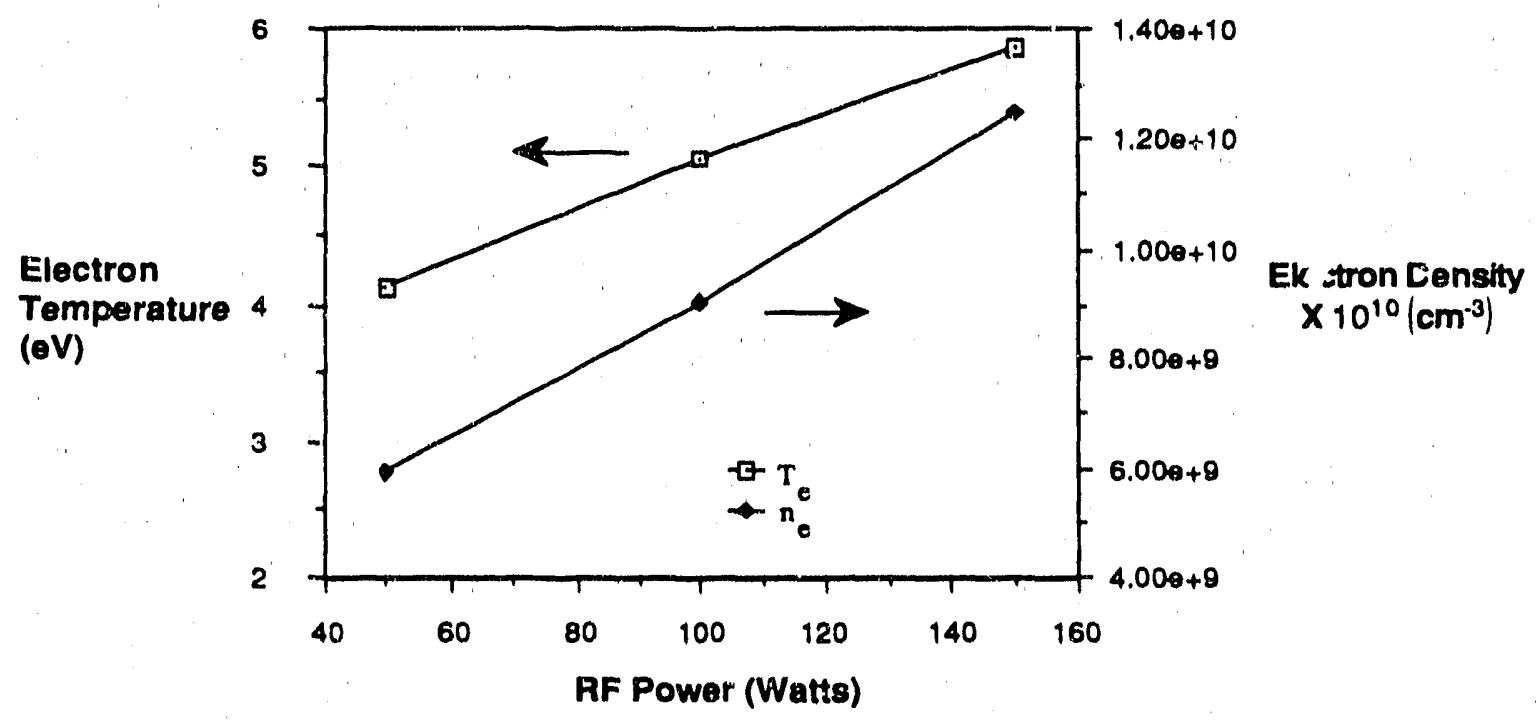

Figure 9. Plot of electron temperature and elactron density versus RF power for oxygen gas in a 1 Torr pressure plasma as determined by Langmuir probe. 


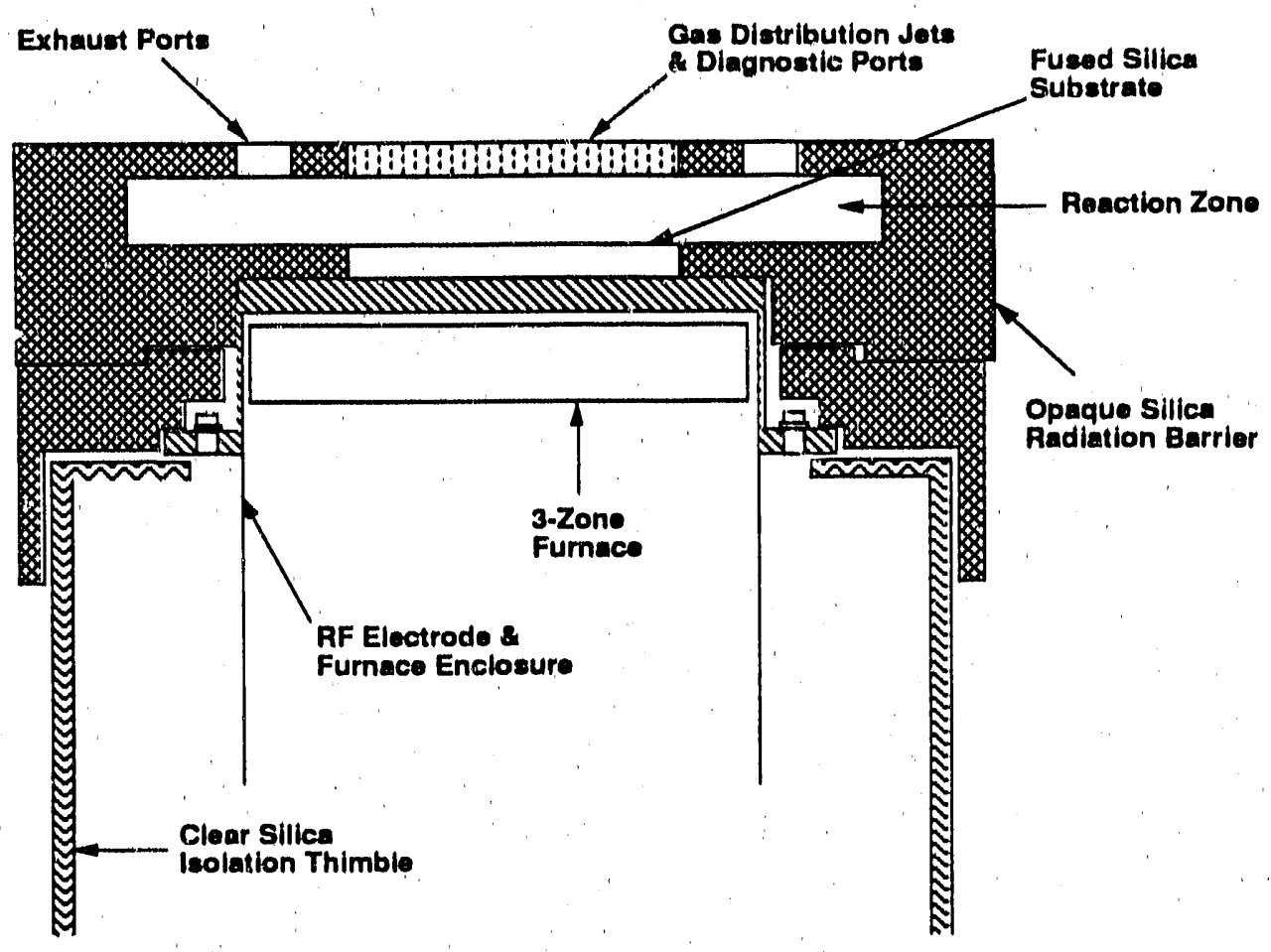

Figure 10. Schematic drawing of PCVD coater reaction chamber.

\subsection{Hardware Development}

Building on the results of the preliminary investigations, a coating system was specified by LLNL and designed and built by Prototech Research Inc. A schematic of the coating chamber is shown in figure 10. It is capable of handling fused silica substrates up to $15 \mathrm{~cm}$ in diameter and $1 \mathrm{~cm}$ thick. The furnace is a 3-zone back-heating system designed to heat the substrates to about $1000^{\circ} \mathrm{C}$. Some details regarding the reaction environment are described in table 2. The "hot wall" reactor is formed by using closed-cell porous silica glass to enclose the reaction volume and absorb radiant energy from the furnace. Gas is injected through a top plate via an array of gas injection ports and exhausted out the top at the periphery of the substrate. The containment vessel for the furnace acts as an electrode for a $24 \mathrm{~kW} 13.56 \mathrm{MHz} \mathrm{RF}$ generator. Plasma confinement is achieved by isolating the walls of the electrode with a silica thimble which is evacuated to less than $10^{-4}$ torr. The absorbing silica provides dielectric insulation to suppress plasma breakdown outside of the reaction chamber. The coating apparatus is located in a clean box to prevent particulate contamination. This coater is designed to be as floxible as possible to allow for design changes to meet coating process demands.

Table 2. Summary of designed operating characteristics of the high temperature, plasma CVD coating system

\begin{tabular}{ll}
\hline Substrate Size & $15 \mathrm{~cm}$ dia. $X 1 \mathrm{~cm}$ thick \\
Oxygen Flow Rate & $0-8 \mathrm{sim}$ \\
$\mathrm{SiCl}_{4}$ Flow Rate & $0-2 \mathrm{sim}$ \\
$\mathrm{GeCl}_{4}$ Flow Rate & $0-500 \mathrm{sccm}$ \\
RF Power & $24 \mathrm{~kW}$ maximum \\
Substrate Temperature & $1000^{\circ} \mathrm{C}$ nominal, $1200^{\circ} \mathrm{C}$ max.
\end{tabular}




\subsection{Cenclusions}

We have recently shown that very high damage threshold dielectric coatings can be made using plasma CVD at high temperatures $\left(=1000^{\circ} \mathrm{C}\right)$ [2]. In this paper we discussed our efforts at scalling this process to large, flat substrates ( $>10$ to $50 \mathrm{~cm}$ diameter). There are four main technical issues that must be solved to successfully implement this coating process:

1. Uniform deposition over a large area $( \pm 1-5 \%)$

2. High deposition rates (1-4 $\left.\mu \mathrm{m} \mathrm{min}^{-1}\right)$

3. Uniform substrate heating at temperatures up to about $1000^{\circ} \mathrm{C}$

4. Minimal dopant diffusion

To address these technical issues we have designed, built and operated a series of test bed reactors to look at mass transport, plasma chemistry, and substrate heating issues. We have identified a flow regime that provides uniform radial mass transfar and hence should give uniform deposition. In this work we have used mathematical models to guide and interpret the experiments. In addition, work is in progress to look at the effects of RF versus microwave driven plasmas on the deposition process and we have begun to identify and refine plasma characterization techniques. Based on these results we have built a large coating system designed to coat substrates up to about $15 \mathrm{~cm}$ in diameter with several thousand quarter-wave layers of alternating doped and undoped $\mathrm{SiO}_{2}$. Details of the coater design specifications have been formulated and givan. The system is expected to be fully operational by mid1990.

\section{References}

[1] Powell, H.T., J.H. Campbeli, J.T. Hunt, W.H. Lowdermilk, J.R. Murray and D.R. Speck, Proceedings of the Workshop on Inertial Confinement Fusion, Varenna, Italy (Sept. 1988). LLNL report UCRL-99517. High Power Nd:Glass Lasers as Drivers for Inertial Confinement Fusion.

[2] Campbell, J.H., J.L. Emmett, R.M. Brusasco, F. Fainer, R.Th. Kersten, V. Paquet and H.-W. Etzkorn, Laser Induced Darnage in Optical Materials, 1989. NTIS special publication (in press). Damage Resistant Optical Coatings Prepared Using High Tomperature Plasma-Chemical-VaporDeposition.

[3] Wilcock, D., C.C. Wright and B.L. Button, Proc. 8th Int. Heat Transfer Conf., 3, 1199, 1986. Multijet Inclined Heat Exchanger Modules: Mass/Heat Transfer and Pressure Loss Characteristics.

[4] Law, H.S. and J.H. Masilyah, Ind. Eng. Chem. Fundam., 23, 446, 1984. Mass Transfer Due to a Confined Laminar Impinging Axisymmetric Jet.

[5] Dzioba, S. G. Este and H.M. Naguib, J. Electrochem. Soc., 129(11), 2537, 1982. Decapsulation and Photoresist Stripping in Oxygen Microwave Plasmas. 
[6] Degenkolb, E.O., C.J. Mogab, M.R. Goldrick, and J.E. Griffiths, Appl. Spectro sC., 30(5), 520, 1976. Spectroscopic Study of Radiofrequerrcy Oxygen Plasina Stripping of Negative Photoresists. I. Ultraviolet Spectrum.

[7] Griffiths, J.E. and E.O. Degenkolb, Appl. Spectrosc., 31(2), 134, 1977. Spectroscopic Study of Radiofrequency Oxygen Plasma Stripping of Negative Photoresists: II Visible Spectrum.

[8] Steinbruchel, Ch., B.J. Curtis, H.W. Lehmann and R. Widmer, IEEE Trans. Plasma Sci., PS-14(2), 137, 1986. Diagnostics of Low-Pressure Oxygen RF Plamsas and the Mechanism for Polymer Etching: A Comparison of Reactive Sputter Etching and Magnetron Sputter Etching.

[9] Thorsress, C.B. and J.A. Britten, LLNL Report, UCRL-102041, October 1989. Mass Transfer Characteristics in Radial-Flow Multijet CVD Reactors.

[10] Chen, F.F., "Electric Probes", Plasma Diagnosicic Techniques, Chapter 4, pp. 113 ff, Academic Press, NY: 1965.

[11] Houtman, G., D.B. Graves and K.F. Jensen, J. Electrochem. Soc., 133, 961, 1986. CVD in Stagnation Point Flow.

[12] Heidenreich, J.E., III, J.R. Paraszczak, M. Moisan and G.J. Sauve, J. Vac. Sci. Technol. B, 5(1), 347,1987 . Electrostatic probe analysis of microwave plasmas used for polymer etching.

[13] Yamagishi, M., K. Mizuno and J. De Groot, J. Quant. Spectrsc. Radiat. Transfer, 40(4), 519, 1988. Spectroscopic Measurements of Air Plasma. 

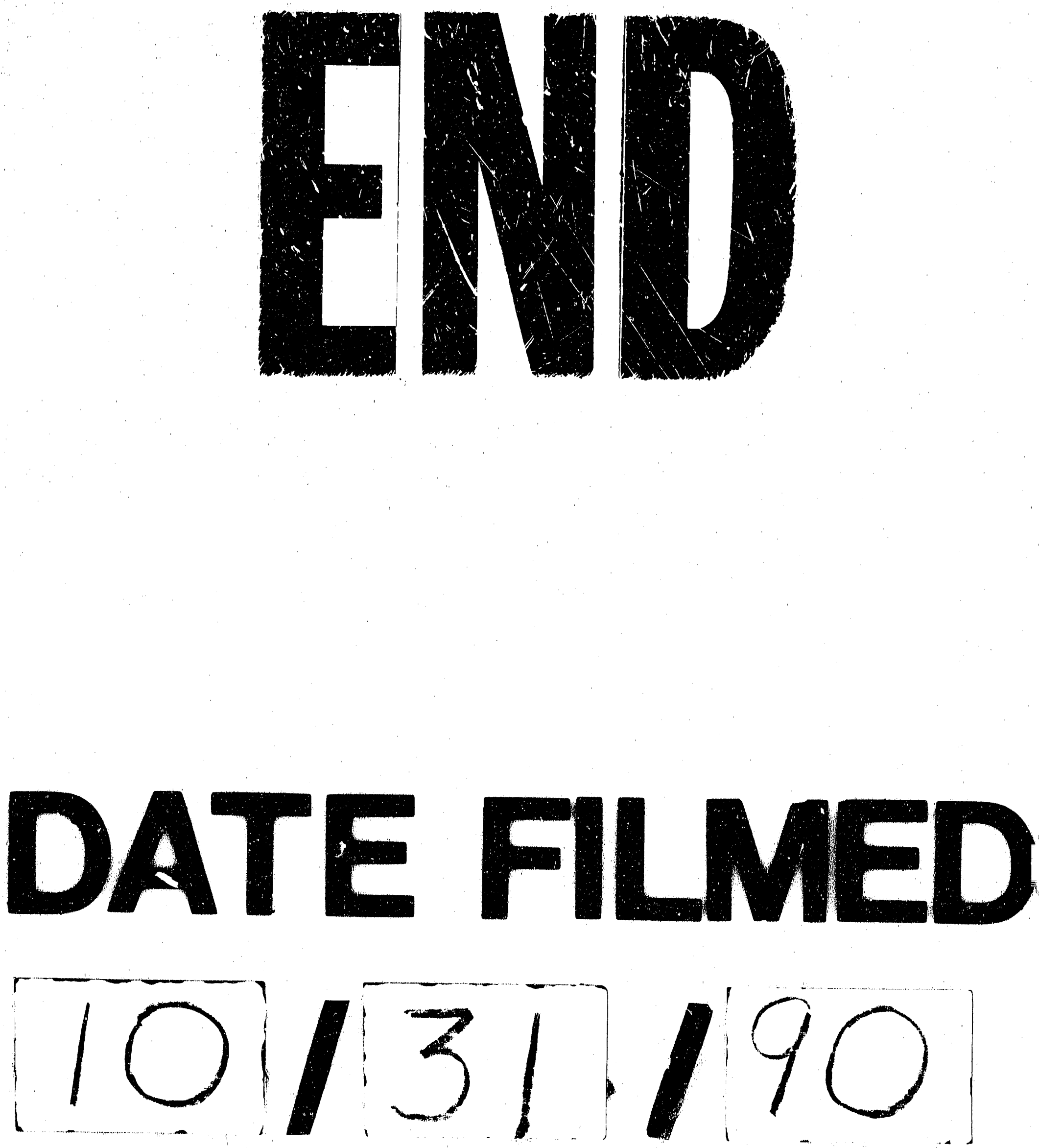
